\title{
An Analytical Study of Air Circulation in Caves
}

\author{
By Arrigo A. Cigna ${ }^{1}$ )
}

With 4 figures and 1 table in the text

\section{Introduction}

The motion of the air inside caves plays an important role in the field of cave meteorology. The causes of the motion can be grouped into two different classes, i.e. static or dynamic ones. Common static causes are those directly connected with a thermodynamic transformation concerning the cave air, such as a variation of temperature, of composition or of pressure. Under the dynamic causes one can cite moving fluids such as water or air. In the present study a hybrid unit system has been preferred because pressures are generally measured in "Torr" (under the conditions of the present work it can be assumed 1 Torr $=1 \mathrm{~mm} \mathrm{Hg}$ ) while other quantities (temperature, length, density, etc.) are reported in technical MKS units. Therefore a dimensionless factor, multiplying pressures in Torr is introduced every time it is necessary. Thus the equations here obtained will be easier employed, without any change, to study the results of many measurements in caves.

In this paper particular emphasis has been given to the quantitative solutions of the air circulation problems. Several authors have described the details of the qualitative characteristics and it is not worth while to repeat them here (Crestani and Anelli, 1939; Eraso, 1962/63; Montoriol Pous, 1951, 1959; Myers, 1953; Trombe, 1952).

\section{Static Causes of Air Motion}

1. The Influence of Temperature, Pressure and Relative Humidity

At first, an equation relating air density $k$, to its temperature, pressure and relative humidity will be written.

1) Viale Medaglie d'Oro, 285, 00136 Roma, Italy. 
The dependance upon the temperature will be given by a factor:

$$
\frac{273.13}{273.13+\Theta}
$$

where $\Theta$ is the air temperature in ${ }^{\circ} \mathrm{C}$.

The pressure factor will be obviously:

$$
\frac{p^{*}}{760}
$$

when $p *$ is the pressure in Torr, corrected to $0^{\circ} \mathrm{C}$. If the humidity effect must also be considered, the pressure factor will be modified as follows :

$$
\frac{p^{*}-M p_{w}}{760}+M k_{w}
$$

where $M$ ist the relative humidity of the air, varying between 0 and 1 , $p_{w}$ is the partial pressure of water vapour in Torr, and $k_{w}$ is the density of water vapour in $\mathrm{kg} / \mathrm{m}^{3}$. By taking into account all these factors, the equation for air density, $k$, will result:

$$
k=\frac{273.13 \times 1.2929}{273.13+\Theta} \times \frac{p^{*}-M p_{w}}{760}+M k_{w}
$$

for dry air with a density at $0^{\circ} \mathrm{C}$, of 760 Torr and standard composition, $k_{o}=1.2929 \mathrm{~kg} / \mathrm{m}^{3}$.

By rearranging:

$$
k=0.464678 \frac{p^{*}-M p_{w}}{273.13+\Theta}+M k_{w}
$$

where $k$ is expressed in $\mathrm{kg} / \mathrm{m}^{3}$. The values of $p_{w}$ and $k_{w}$ as functions of the temperature are reported in Table 1 (Anon, 1926). The differences between outside and inside air density may cause the circulation of the air in caves both with a single entrance and with many entrances at different levels. In the first case air will flow inward along the floor or the roof of the passage-way, and return outward along the roof or the floor, according to the sign of the difference of density. In the second case the air-flow will be directed upward or downward depending on the difference of density, as usual. 
Table 1

(Anon., 1926)

\begin{tabular}{rcc|ccc}
\hline${ }^{\circ} \mathrm{G}$ & $\begin{array}{c}p_{w} \\
(\text { Torr }) \\
\text { at } 0{ }^{\circ} \mathrm{C}\end{array}$ & $\begin{array}{c}k_{w} \\
\left(\mathrm{~kg} / \mathrm{m}^{3}\right)\end{array}$ & ${ }^{\circ} \mathrm{C}$ & $\begin{array}{c}p_{w} \\
(\text { Torr }) \\
\text { at } 0^{\circ} \mathrm{C}\end{array}$ & $\begin{array}{c}k_{w} \\
\left(\mathrm{~kg} / \mathrm{m}^{3}\right)\end{array}$ \\
\hline-10 & 1.95 & 0.00217 & 10 & 9.21 & 0.00941 \\
-9 & 2.13 & 0.00236 & 11 & 9.8 & 0.0100 \\
-8 & 2.32 & 0.00256 & 12 & 10.5 & 0.0107 \\
-7 & 2.53 & 0.00278 & 13 & 11.2 & 0.0114 \\
-6 & 2.76 & 0.00301 & 14 & 12.0 & 0.0121 \\
-5 & 3.01 & 0.00327 & 15 & 12.8 & 0.0128 \\
-4 & 3.28 & 0.00354 & 16 & 13.6 & 0.0137 \\
-3 & 3.57 & 0.00384 & 17 & 14.5 & 0.0145 \\
-2 & 3.88 & 0.00415 & 18 & 15.5 & 0.0154 \\
-1 & 4.22 & 0.00448 & 19 & 16.5 & 0.0163 \\
0 & 4.58 & 0.00484 & 20 & 17.5 & 0.0173 \\
1 & 4.93 & 0.00520 & 21 & 18.6 & 0.0183 \\
2 & 5.29 & 0.00557 & 22 & 19.8 & 0.0194 \\
3 & 5.69 & 0.00596 & 23 & 21.1 & 0.0206 \\
4 & 6.10 & 0.00637 & 24 & 22.4 & 0.0218 \\
5 & 6.54 & 0.00681 & 25 & 23.8 & 0.0231 \\
6 & 7.01 & 0.00726 & 26 & 25.3 & 0.0245 \\
7 & 7.51 & 0.00776 & 27 & 26.8 & 0.0258 \\
8 & 8.05 & 0.00828 & 28 & 28.4 & 0.0273 \\
9 & 8.61 & 0.00883 & 29 & 30.1 & 0.0288
\end{tabular}

In general the distinction between the two cases is very easy. But it seems to be useful, from the point of view of the present work, to distinguish them by means of the following integral which gives the air-flow through a cross section of a passage-way:

$$
\int_{S} u d s\left\{\begin{array}{c}
=0 \text { (closed system with single entrance) } \\
\neq 0 \text { (system with } 2 \text { or more passage-ways } \\
\text { through to surface openings) }
\end{array}\right.
$$

where $u$ ist the mean velocity of the air and $d s$ in an element of surface, the integral being extended to the whole cross section. In the first case (closed system) it is rather difficult to measure the value of the motive pressure produced by the difference of the density on account both of the small values reached and of the strong influence of the shape of the cave on the circulation of the air. It may be of some interest to remember here an equation giving the distribution of the air 
temperature ${ }^{2}$ ) along the main axis of a cave (Cigna, 1961). In such an equation it is possible to calculate the value of the product $d_{2} \cdot u$ from the other parameters obtained by direct measurements. If the velocity of the air $u$ is known too, the value of the equivalent diameter $d_{e}$ of the cavity can be deduced. This diameter is defined as the diameter of the imaginary duct extending in the part of the passageway through which the entering air only is flowing. In the case of a cave with two entrances at different levels (Fig. 1) it is possible to

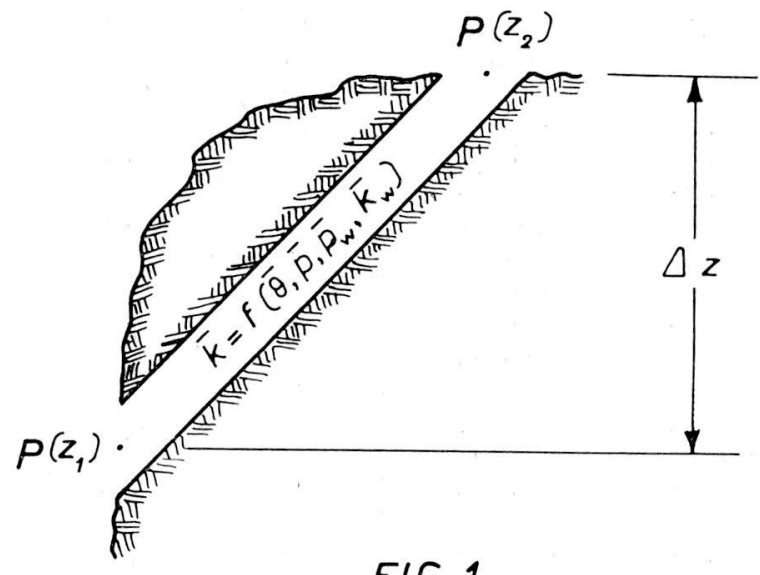

FIG. 1

Fig. 1. Schematic cave with two entrances at different levels.

consider the circulation of the air in a more quantitative manner. Indeed a draught is caused by the difference in density between a column of air within the cave and a corresponding column of air of equal dimension outside the cave.

In general, if $p\left(z_{2}\right)$ is the atmospheric pressure at the higher entrance, $p\left(z_{1}\right)$ the corresponding pressure at the lower one and $\Delta z=z_{2}-z_{1}$ in metres, the following equation will be obtained:

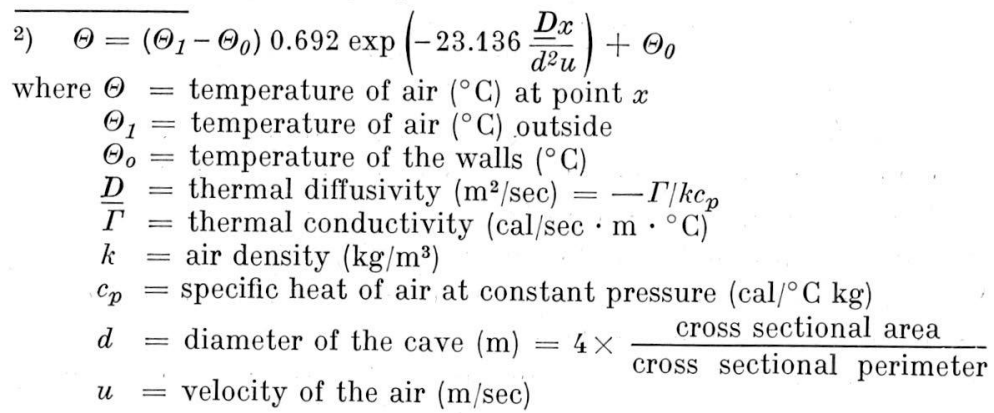




$$
p\left(z_{2}\right)+k \Delta z \lessgtr p\left(z_{1}\right)
$$

If the sign $>$ holds, air circulation inside the cave will be downward, and the reverse if sign $<$ holds. By introducing the pressure difference, $\Delta p=p\left(z_{1}\right)-p\left(z_{2}\right)$, equation (7) can be written:

$$
\bar{k} \Delta z-13.596491 \Delta p \lessgtr 0
$$

The factor 13.596491 has been introduced because the values of $k$ and $z$ are expressed in units of the MKS system while $\Delta p$ is in Torr, as pointed out in the introduction.

To substitute equation (5) in (8) it is necessary to calculate $\Theta, p$, $M, p_{w}$ and $k_{w}$ appearing in equation (5).

Temperature $\Theta$ distribution along the main axis of the cave must be known. This condition is less restrictive than it appears because it is well known that the temperature gradient inside the caves is important only near the entrances while it is almost constant (and very often negligible too) in the other parts. Therefore it is possible to calculate the average temperature $\bar{\Theta}$ with the integral

$$
\bar{\Theta}=\frac{\int_{0}^{L} \Theta(x) d x}{L}
$$

where $x$ is chosen along the main axis of the cave, $L$ is the real length of the cave between the two entrances and $\Theta(x)$ is the temperature of air inside the cave at a distance of $x$ metres from one of the entrances.

Integral (9) can be easily calculated by graphical methods (Pipan, 1956).

Also the average pressure can be calculated in the same way with an analogous integral. Nevertheless the pressure gradient inside the cave is taken to be constant in this paper. In most cases it is quite sufficient to calculate the average pressure $p *$ corrected to $0^{\circ} \mathrm{C}$ as follows:

$$
\bar{p} *=\frac{p^{*}\left(z_{1}\right)-p *\left(z_{2}\right)}{2}
$$

In the same way the average relative humidity $\bar{M}$ can be also determined by taking into account, the small differences among its values in different points of the cave.

The corresponding average partial pressure $\bar{p}_{w}$, and the average density, $\bar{k}_{w}$, of water vapour can be found in Table 1 when $\bar{\Theta}$ is determined.

By taking into account the average quantities which have been calculated, equation (5) can be substituted in equation (8) and the resulting pressure on a cross section of the cave at the lower entrance is given by:

$$
\left(0.464678 \frac{\bar{p}^{*}-\bar{M} \bar{p}_{w}}{273.15+\bar{\Theta}}+\bar{M} \cdot \bar{k}_{w}\right) \Delta z-13.596491 \cdot \Delta p \lessgtr 0
$$


Of course equation (11) is valid for air having the standard chemical composition. In case of a different composition (e.g. in caves connected with volcanic phenomena) the value $k_{o}=1.2929 \mathrm{~kg} / \mathrm{m}^{3}$ should be replaced by the correct one and the factor in equation (11) recalculated.

The heigt $\Delta z$ of a karstic system, when only the lower entrance is known, can be estimated from the values of the air density inside $\left(k_{i n}\right)$ and outside $\left(k_{o u t}\right)$ and from the measurement of the pressure $p_{m}$ resulting from the difference of the densities. From equation (8):

$$
13.596491 \cdot p_{m}=13.596491 \cdot \Delta p-k_{i n} \cdot \Delta z
$$

when $p_{m}$ and $\Delta p=p\left(z_{1}\right)-p\left(z_{2}\right)$ are measured in Torr. But

and therefore

$$
13.596491 \cdot \Delta p=k_{\text {out }} \cdot \Delta z
$$

$$
13.596491 \cdot p_{m}=\left(k_{o u t}-k_{\text {in }}\right) \Delta z
$$

Thus, $\Delta z$ can be easily calculated:

$$
\Delta z=\frac{13.596491 \cdot P_{m}}{k_{o u t}-k_{\text {in }}}
$$

The effective values of $k_{i n}$ and $k_{\text {out }}$ can be determined by substituting in equation (5) the estimated average values of pressure, humidity and temperature of the air column inside and outside. Of course, the inaccuracy of such estimations causes an error in the determination of $\Delta z$. Nevertheless even a rough determination of $\Delta z$ can sometimes be interesting for the development of further researches on the karstic system under examination.

\section{The Influence of Atmospheric Pressure Variations}

Let us consider a cave consisting of a rather big hall connected to the outside only through a single small passage (Fig. 2). If the volume of the air inside the cave is $V$ and its pressure is $p$ (equal to the pressure at the entrance in equilibrium conditions), if the temperature is kept constant, the product $p V$ will also be constant. Therefore if pressure $p$ varies, also the colume $V$ changes and an air current will be established at the entrance. Obviously this current will be directed inside if the pressure is increasing and outside if the pressure is decreasing (Polli, 1956). If $S$ is the cross section of the entrance, $p_{1}$ and $V_{1}$ the pressure and volume of the air at time $\tau_{1}$, and $p_{2}$ the pressure at time $\tau_{2}$ the volume of the same amount of air will also vary according to:

$$
p_{1} V_{1}=p_{2} V_{2}=\text { constant }
$$




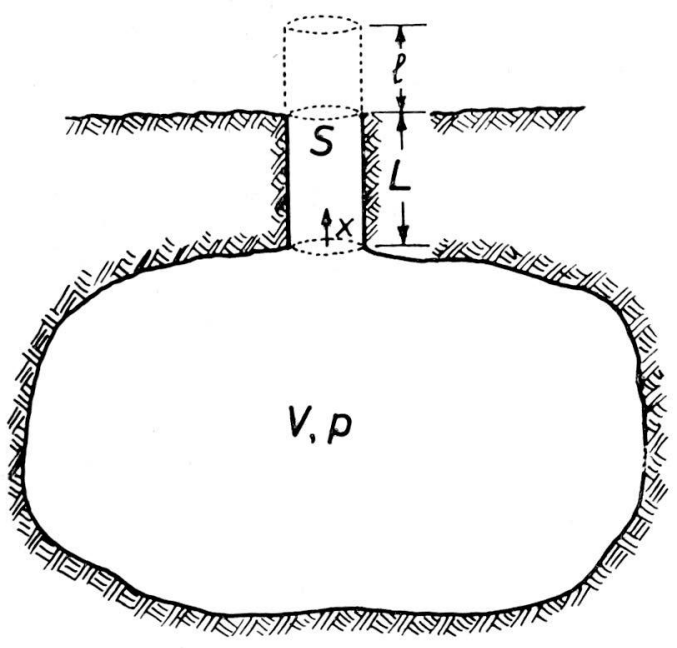

FIG. 2

Fig. 2. Barometric cave, consisting in a big cavity connected to the surface through a small passage-way of length $L$.

and hence:

$$
V_{2}=V_{1} \frac{p_{1}}{p_{2}}
$$

Let be $p_{2}<p_{1}$, then

$$
S l=V_{2}-V_{1}=V_{1}\left(\frac{p_{1}}{p_{2}}-1\right)
$$

where $l$ is the length of the imaginary cylinder with section $S$ containing the air exhausted from the cave. Then the velocity of the air current is :

$$
u=\frac{l}{\tau_{2}-\tau_{1}}=\frac{V_{1}\left(p_{1} / p_{2}-1\right)}{S\left(\tau_{2}-\tau_{1}\right)}
$$

Obviously if $p_{2}>p_{1}$ equations (17) and (18) become, respectively:

$$
\begin{aligned}
& S l=V_{1}-V_{2}=V_{1}\left(1-\frac{p_{1}}{p_{2}}\right) \\
& u=\frac{l}{\tau_{2}-\tau_{1}}=\frac{V_{1}\left(1-p_{1} / p_{2}\right)}{S\left(\tau_{2}-\tau_{1}\right)}
\end{aligned}
$$


It is interesting to remember the possibility of measuring the volume of the cave without entering it. Equations (18) and (20) can be solved with respect to $V_{1}$ (coincident with the volume of the cave):

$$
V_{1}=\frac{p_{2} \cdot S \cdot 1}{\left(p_{1}-p_{2}\right)}
$$

Equation (22) gives reliable results only if $p_{1}$ and $p_{2}$ are measured under equilibrium conditions (i.e. at time $\tau_{1}$ and $\tau_{2}, u=0$ ) and the period $\tau=\tau_{2}-\tau_{1}$ is short enough to avoid any temperature change. This condition is besser achieved when $p_{2}<p_{1}$, so that the outgoing air is certainly at the same temperature as the air inside. The pressure variation should be measured with a sensitive microbarometer and section $S$ can be easily measured by modifying the entrance of the cave with a sort of a suitable diaphragm in order to have a regular geometrical cross-section; at last $l$ is read directly with an anemometer placed in the same cross section. Of course the anemometer readings must be averaged over the whole surface.

The cave considered at the beginning of this paragraph can also be studied from another point of view (Fig. 2). Let $V$ be the volume of the hall, $p$ and $k$ the pressure and the density of the inside air and $S$ the cross-section area of the passage, supposed to be constant all over the length $L$ of the passage. In such conditions air oscillations through the entrance are possible. If the volume $S l$ is much smaller than $V$ the air mass $S \cdot l \cdot k$ contained in the tube can be considered to move as a rigid piston under the effect of the differences between the inside and outside pressures. The oscillation of air around the equilibrium point is then defined by the displacement $x$ of a layer from its rest position.

For a pressure variation $\Delta p$ it holds that:

$$
\Delta p=-\frac{\varepsilon}{V} \Delta V=-\frac{\varepsilon}{V} S x
$$

where $\varepsilon$ is the modulus of compressibility of the air. The motive force is

$$
S \Delta p=-\frac{\varepsilon S^{2}}{V} x
$$

and from the motion law $F=m \cdot a$ it follows:

$$
\operatorname{Slk} \frac{d^{2} x}{d t^{2}}=-\frac{\varepsilon S^{2}}{V} x
$$

i.e. :

$$
\frac{d^{2} x}{d t^{2}}+\frac{\varepsilon S}{V l k} x=0
$$


which is the equation of an oscillating motion. The period of the motion is:

$$
t=\frac{2 \pi}{U} \sqrt{\frac{V L}{S}}
$$

where $U=\sqrt{\varepsilon / k}$ is the velocity of sound.

Then it is possible to determine the volume $V$ of the barometric cave by simple measurements of the length $L$ and of the section $S$ of the passage connecting the cave with the outside and of the period $t$ of an oscillation of the air current through the passage itself.

The volume $V$ in $\mathrm{m}^{3}$ is given by:

$$
V=2930 \frac{t^{2} S}{L}
$$

deduced from equation (27) when $U=340 \mathrm{~m} / \mathrm{sec}$ and $t$ is expressed in seconds, $S$ in $\mathrm{m}^{2}$ and $L$ in $\mathrm{m}$. Of course equation (27) is valid under the condition of having a rather regular entrance passage. The value of the cross-section $S$ must refer to that part of the section of the passage where the air is really flowing. When $V$ is some hundreds of thousands of $\mathrm{m}^{3}, S$ a few $\mathrm{m}^{2}$ and $L$ some tens of metres, $t$ is of the order of some tens of seconds. If in some particular cases the length of the passage is short (very few metres) and the air velocity rather high, the value of $L$ should probably be estimated by determining the length of the air

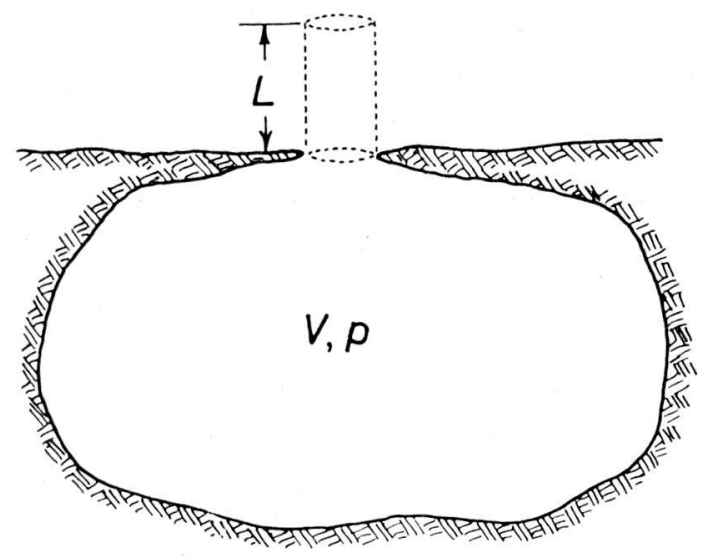

FIG. 3

Fig. 3. Same as in Fig. 2, except for the length of the passage-way which is negligible. 
column moving coherently and extending outside the passage under consideration (Fig. 3).

Pressure variations may also affect the air circulation considered in section 1. According to the sign of pressure variation the theoretical draught of equation (11) can obviously be increased or reduced by a considerable amount.

Therefore the implications of equation (11) are valid only for equilibrium conditions of atmospheric pressure.

\section{Dynamic Causes of Motion}

\section{The Influence of Moving Fluids}

\section{(a) Movement Inside the Cave}

As has already been stated in the introduction moving fluids can be classified as dynamic causes of the motion of the air in a certain part of a cave. Only the general circulation will be considered here. In other words the strictly local circulation of the air around a waterfall for instance will not be studied now, on account of its reduced interest from the point of view of cave meteorology.

In general, Bernoulli's theorem can be applied, with some approximations to the motion of a fluid (air or water) in a cave. The most important consequence is a suction effect induced in some parts of a cave with a suitable shape. Thus, a primary air- or water-current flowing through a narrow passage may cause an induced current in another passage connected to the first one at a certain angle (Fig. 4). The characteristics of the draught induced in such a way are quite peculiar to the geometrical features of the passages and therefore it is impossible to develop any quantitative study of the phenomenon. It can only be said that for each single situation under some approximations a draught $p_{m}$ is proportional to the primary fluid (air or water) velocity $u$ :

$$
p_{m}=f_{1} \times u_{m o t i v e}
$$

where $f_{1}$ is a constant with an unpredictable value. However, the measurement of $p_{m}$ can be rather difficult on account of the small values achieved. Generally a simple correlation between the velocity of the "motive" air current and the velocity of the induced air current will be determined with direct measurements:

$$
u_{\text {induced }}=f_{2} \times u_{\text {motive }}
$$



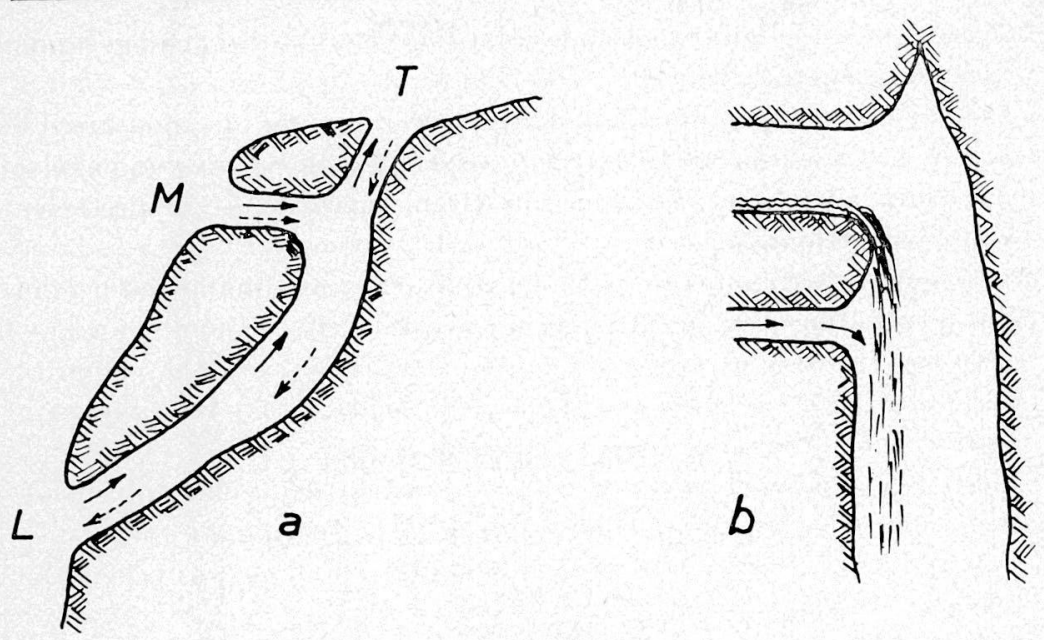

\section{FIG. 4}

Fig. 4. a) A constant direction air-flow is induced through $M$ by the flow between $T$ and $L$. (solid arrows: Winter; dotted arrows: Summer). b) An air-flow induced by a waterfall.

Such a relation may be of some interest for the study of a karstic system of the type shown in Fig. 4. A freely running stream frequently induces an air current, on account of the friction between the water and air surfaces. Under particular conditions (waterfalls, etc.) the air may be carried along by the flowing water in the form of bubbles. When the amount of water is large in comparison with the cross-section of the passage, which it is flowing through, the amount itself influences the $u_{\text {induced }}$ so that equation (30) is no longer valid. A quantitative study is only possible when many sets of measurements are available in a single cave.

\section{(b) Movement Outside the Gave}

The action of the wind on the circulation of the air inside a cave is well known to every caver. As it has been pointed out in the preceding paragraph a mathematical treatment of such an influence is nearly impossible on account of the great variation in the geometrical features of the cave entrance and in the characteristics of the wind itself. The measurements of the different effects is sometimes difficult and great care must be paid to avoid any undesired modification of the phenomenon. In the case of single entrance caves a correlation between wind characteristics and air circulation inside the cave will be rather doubt- 
full because of the many factors involved. On the contrary, for systems with two or more entrances at different levels the effect of the wind is generally more important and equation (11) may be of some interest inasmuch as it is possible to determine the effect due to the wind alone, by a simple change of the place of the measurement of air pressure. Two barometric measurements performed a very few metres above and below the entrance of a pothole, whilst they are unaffected by the height variation, give by difference, the value of the depression produced by the wind blowing outside. Its comparison with the values of the velocity and the direction of the wind leads to the determination of equations of the same type as equation (29).

The effects induced by waterfalls or influent streams entering a cave can be considered in the same way. As it has been pointed out in subsection (a) the amount of water may also play an important role in the creation of an air current.

\section{Conclusion}

A mathematical treatment of problems concerning air circulation in caves seems at first to be rather difficult. But in such a way, cave meteorology can produce a good contribution to the knowledge of karstic systems.

In the first period of development of cave meteorology, only qualitative information could be obtained. At present, with the help of the mathematical treatment it is possible to draw quantitative information.

For instance, the method here reported for the determination of a cave volume according to measurements performed at the entrance of the cave only, is a useful tool for the easy detection of important underground systems.

In the near future many of these tools will be available to experts in cave meteorology.

\section{ACKNOWLEDGMENTS}

I am very grateful to my friends, Dr. F. G. Giorcelli for the useful discussion during the preparation of this paper and Dr. G. T. Warwick who carefully edited the English text.

\section{SUMMARY}

The different types of air circulation in caves are classified according to the origin of the circulation, as either static or dynamic. 
In a cave static causes are:

(a) differences between inside and outside air density owing to:

(i) air temperature,

(ii) relative humidity,

(iii) chemical composition;

(b) atmospheric pressure variation.

Dynamic causes are:

(a) moving fluids:

(i) inside the cave,

(ii) outside the cave.

Whenever possible the above mentioned phenomena have been considered from a mathematical point of view in order to obtain equations relating the different quantities involved.

\section{RIASSUNTO}

Vengono presi in considerazione i vari tipi di circolazione dell'aria nelle grotte a seconda delle cause che danno luogo a tale circolazione. Queste cause vengono distinte in statiche e dinamiche.

In una certa grotta le cause statiche sono:

(a) differenze di densità tra l'aria interna e quella esterna, dovute a:

(i) temperatura dell'aria,

(ii) umidità relativa,

(iii) composizione chimica;

(b) variazione della pressione atmosferica.

Le cause dinamiche sono:

(a) fluidi in movimento:

(i) entro la grotta,

(ii) all'esterno.

Ogni qual volta é stato possibile sono stati considerati i problemi sopra accennati da un punto di vista matematico, al fine di ottenere delle equazioni correlanti le varie grandezze che entrano in gioco.

\section{REFERENCES}

Anon. (1926) - "Hutte", 1: 514, U. Hoepli, Milano.

Cigna, A. A. (1961) - Air Temperature Distributions near the Entrance of Caves. Proc. Symp. Int. Spel., Varenna 1960, 2: 259-267, Mem. V. Rass. Spel. Ital., Como.

Crestani, G., and Anelli, A. (1939) - Ricerche di meteorologia ipogea nelle Grotte di Postumia. Min. Lavori Pubblici, Magistrato alle Acque, Ufficio Idrografico, Pubbl. n. 143: 1-162, Roma. 
Eraso, A. (1962/63) - Ideas sobre la climatica subterranea. Estudios del Gr. Espeleologico Alavés: 21-41.

Montoriol Pous, J. (1951) - Meteorologia hipogea. Urania, 228: 1-22, Tarragona.

- (1959) - La distribucion térmica en las formaciones hipogeas y sus consecuencias en cuanto a la dinamica del aire. Mem. Asamblea Regional de Espeleologia : 3-27, Carranza (Vizcaya).

Myers, J. O. (1953) - Cave Physics, Meteorology, in: C. H. D. Cullingford (Ed.) - British Gaving: 144-151, Routledge \& Kegan Paul Ltd., London.

Pipan, L. (1956) - Ricerche preliminari di meteorologia ipogea nelle grotte del Carso triestino. Atti VI Congr. Naz. di Spel. 1954:219-224, Trieste.

Polli, S. (1956) - La Grotta Gigante del Carso Triestino quale cavità barometrica. Atti VI Congr. Naz. di Spel. 1954: 277-286, Trieste.

Trомве, F. (1952) - Traité de Spéléologie : 92-127, Payot, Paris. 